AperTO - Archivio Istituzionale Open Access dell'Università di Torino

A novel human fibronectin cryptic sequence unmasked by the insertion of the angiogenesisassociated extra type III domain B

This is a pre print version of the following article:

Original Citation:

Availability:

This version is available http://hdl.handle.net/2318/1652596

since 2018-05-22T12:45:48Z

Published version:

DOI:10.1002/ijc. 24473

Terms of use:

Open Access

Anyone can freely access the full text of works made available as "Open Access". Works made available under a Creative Commons license can be used according to the terms and conditions of said license. Use of all other works requires consent of the right holder (author or publisher) if not exempted from copyright protection by the applicable law. 


\section{(3) \\ UNIVERSITÀ DEGLI STUDI DI TORINO}

This is an author version of the contribution published on:

Questa è la versione dell'autore dell'opera:

A novel human fibronectin cryptic sequence unmasked by the insertion of the angiogenesis-associated extra type III domain B

Balza E, Sassi F, Ventura E, Parodi A, Fossati S, Blalock W, Carnemolla B, Castellani $P$, Zardi L, Borsi L

Int J Cancer. 2009 Aug 15;125(4):751-8. DOI: 10.1002/ijc.24473

The definitive version is available at:

La versione definitiva è disponibile alla URL:

[http://onlinelibrary.wiley.com/doi/10.1002/ijc.24473/abstract?systemMessage=Wil ey+Online+Library+usage+report+download+page+will+be+unavailable+on+Friday+ $24 t h+$ November $+2017+a t+21 \% 3 A 00+E S T+\% 2 F+02.00+G M T+\% 2 F+10 \% 3 A 00+S G T+\% 2$ 8 Saturday+25th+Nov+for+SGT+] 


\title{
A NOVEL HUMAN FIBRONECTIN CRYPTIC SEQUENCE UNMASKED BY THE INSERTION OF THE ANGIOGENESIS-ASSOCIATED EXTRA TYPE III DOMAIN B
}

Enrica Balza1, Francesca Sassi1, Elisa Ventura2, Arianna Parodi2,3, Sara Fossati2,3, William Blalock2,3,

Barbara Carnemolla1,2,3,4, Patrizia Castellani1, Luciano Zardi2,3* and Laura Borsi1

1Laboratory of Cell Biology, Istituto Nazionale per la Ricerca sul Cancro, Genova, Italy

2Laboratory of Recombinant Therapeutic Proteins, Centro di Biotecnologie Avanzate, Genova, Italy

3Unit of Innovative Therapies, Istituto Giannina Gaslini, Genova, Italy

4Laboratory of Immunology, Istituto Nazionale per la Ricerca sul Cancro, Largo Rosanna Benzi 10, 16132 Genova, Italy

\begin{abstract}
The angiogenesis-associated extra-domain B (EDB) of fibronectin (FN) is a complete type III repeat of 91 amino acids. Its expression is modulated by the alternative splicing pattern of the FN premRNA. FN containing the EDB (B-FN) is undetectable in tissues of healthy adults, with rare exceptions such as the female reproductive system where tissue remodeling and angiogenesis are recurrent physiological processes. On the contrary, B-FN is expressed at high levels in neoplastic tissues and during angiogenesis; consequently, it is considered an excellent marker of angiogenesis. Here, we report on a novel FN cryptic sequence, localized on the FN type III repeat 8 (immediately downstream of the EDB) that is unmasked by the insertion of the EDB. This sequence is specifically recognized by the high-affinity monoclonal antibody, C6, that selectively recognizes BFN by means of ELISA, immunohistochemical and Western blot assays. The variable regions of C6 were cloned and a divalent covalently linked mini-antibody was generated. Biodistribution studies using the radioiodinated C6 mini-antibody on tumor-bearing mice demonstrated an efficient tumor targeting. This antibody represents a new tool for the study of the potential biological functions of hindered sequences that the inclusion of the EDB renders accessible, and likewise makes its epitope an additional angiogenesis target.
\end{abstract}

Key words: oncofetal fibronectin; angiogenesis; tumor targeting; monoclonal antibodies; cryptic epitopes

\section{Introduction}


During tumor progression, the extracellular matrix (ECM) of the normal tissues in which a tumor grows is remodeled through proteolytic degradation and by neosynthesis of new components by both neoplastic and stromal cells, thereby generating a "tumoral ECM," which differs from that of normal tissues. It appears that this tumoral ECM provides a more suitable environment for tumor progression (inductive and/or instructive), of which angiogenesis is a crucial step.1-3 The tumoral ECM contains several “tumor-associated”' antigens, which include the large isoforms generated by a modified pattern of alternative splicing of the pre-mRNA of tenascin and fibronectin (FN).4-10 FNs are high-molecular-mass adhesive glycoproteins (for reviews see 3,11,12) present in the ECM and body fluids, constituted by a dimer composed of 2 subunits of about $250 \mathrm{kDa}$ linked at the Ctermini by 2 disulfide bonds. Each monomer consists of 3 types of repeating units: 12 FN repeats of type I (about 40 amino acids each), 2 type II (about 60 amino acids) and 15-17 type III (about 90 amino acids) (see Fig. 1). FN mediates a wide variety of cellular interactions and is involved in a number of processes, such as cell adhesion, the establishment and maintenance of normal cell morphology, cell migration, growth and differentiation. It interacts with several other proteins of the ECM and of the cell surface, including collagen, heparin, fibrin and cell membrane receptors. Finally, FN can be a ligand for numerous integrins, including the classic FN receptor alpha5-beta1 on the RGD sequence on repeat III-10.13 FNs are the product of a single gene localized on chromosome 2,14 but different isoforms arise from the alternative splicing of the pre-mRNA in 3 sites called IIICS (type III connecting sequence), EDA (a complete type III repeat, extra domain A) and EDB (a complete type III repeat, extra domain B) (Fig. 1). For EDA and EDB exon usage or skipping leads to inclusion or exclusion of these type III repeats. In cultured transformed cells and in malignancies, the splicing pattern of FN pre-mRNA is altered,4,5,7,9,10,15-18 leading to an increased expression of FN isoforms containing the domains regulated by alternative splicing. In particular, the B-FN, which, with some very rare exceptions, is undetectable in normal adult tissues, exhibits a much greater expression in fetal and tumor tissues, as well as during wound healing.5,16,19,20 Furthermore, B-FN is accumulated around neovasculature during angiogenic processes21,22 and thereby provides a marker for angiogenesis. The generation of a monoclonal antibody (mAb), BC1, highly specific for the human B-FN isoform,5 has allowed all of the early extensive immunohistochemical studies that have clearly established the outstanding presence of BFN in different kinds of pathologies, including various forms of cancer and all angiogenesisassociated pathologies.18,22 However, this antibody does not recognize an epitope within the EDB, but one localized on the type III repeat 7 that precedes the EDB (Fig. 1). This epitope is cryptic in FN molecules lacking the EDB and unmasked in molecules containing this domain.23 A mAb, IST6, was also generated that is highly specific for EDB-free FN and thus does not react with B- 
FN. Using these 2 mAbs, we demonstrated that the insertion of the EDB in FN molecules leads to a conformational modification that unmasks hindered sequences and hinder other sequences.23 Here, we now report on a novel sequence localized on the type III repeat 8 (the one immediately downstream of the EDB, Fig. 1), which is cryptic when the EDB is omitted and unmasked when it is included within the FN molecule. We also describe a high-affinity murine monoclonal antibody, C6, specific for this epitope. Using the cloned variable regions of this mAb, we produced a divalent, covalently bound mini-antibody and demonstrated its ability to target B-FN in vivo in tumorbearing mice.

\section{Material and methods}

\section{Monoclonal antibodies}

mAbs specific for human FN were prepared as previously described24 by fusion of SP2/0 murine myeloma cells (ATCC, American Type Culture Collection, Rockville, MD) with splenocytes from immunized Balb/C mice (Charles River, Italy). ELISA, SDS-PAGE, Western blotting and size exclusion chromatography were performed as described.25 The mAb BC1 and the human recombinant antibody CGS1 have been previously described.5,23,26 The Mab BC1 recognizes BFN reacting with a cryptic epitope on the repeat III7 unmusked when EDB is inserted into the FN molecule. The recombinant single-chain variable fragment (scFv) CGS1 reacts directly with EDB. The binding properties of the mAb C6 to the FN recombinant fragment 7.EDB.8.9 were studied by real-time interaction analysis with surface plasmon resonance detection using a BIAcore 1000 instrument (Biacore AB, Uppsala, Sweden) as previously reported by Tarli et al.27

\section{Purification of plasma and cellular FNs and FN recombinant fragments FN}

was purified as previously described16 from human plasma and from conditioned media of SV40transformed human fibroblasts WI38VA grown in Eagle's minimum-essential medium supplemented with 10\% fetal calf serum (FCS) (Flow Laboratories, Irvine, Scotland, UK), depleted of bovine FN by passage through a large capacity gelatin-Sepharose column (GE Healthcare BioSciences, Milan, Italy). Recombinant FN fragments containing various FN type III homology repeats (Fig. 1) were produced by PCR using the DNA clones FNIII 2-11 (ED-B1) and FNIII 2-11 (ED-B-), previously described,26 as template and appropriate primers. PCR products were cloned into the pQE-12 vector using the QIAexpress kit and expressed in M15 competent bacteria cells. All cloned cDNAs were sequenced on both strands. Recombinant proteins were purified by Ni-NTA 
columns (Qiagen, Hilden, Germany) by use of the His6 tag appended at the C-terminus of the FN fragments, according to the manufacturer's instructions.

\section{Tissues and immunohistochemical procedures}

Normal and neoplastic human tissues were obtained from samples taken during the course of therapeutic surgical procedures. Specimens of the F9 murine teratocarcinoma and of the human melanoma SKMEL-28 (ATCC) were obtained by subcutaneous injection with 23106 cells in 6week-old SCID Beige SPF/VAF mice. Animals were sacrificed when tumors reached a diameter of about $1.0 \mathrm{~cm}$. SCID Beige SPF/VAF mice were used to avoid background in immunohistochemical experiments because of endogenous immunoglobulins. The immunohistochemical procedure was performed as previously described.21 A biotinylated goat antimouse IgG (Bio-SPA, Milan) was used as secondary antibody for murine monoclonal antibodies BC1 and C6, whereas for the recombinant antibody CGS1, we used the anti Myc-tag 9E10 murine monoclonal antibody (ATCC) followed by the biotinylated goat anti-mouse IgG. For negative controls, the primary antibodies were replaced by PBS or additioned with an excess of antigen (7.EDB.8.9).

\section{Preparation of the C6-UG fusion protein (mini-antibody)}

Total RNA was purified using the procedure reported by Chomczynski and Sacchi.28 The cDNA of the variable regions of C6 mAb was obtained by RT-PCR using total RNA purified from C6 hybridoma cells, as template, and the primers: 50gatattgtgatga cccagtctcca30 (fw) and 50tggatacagttggtgcagc30 (rev) for VL; $50 \operatorname{aggtg(c)c(a)ag(a)ctgcagg(c)agtct(a)gg30~(fw)~and~}$ 50 ggccagtggata gac30 (rev) for $\mathrm{VH}$. The resulting amplification products were then sequenced on both strands and further amplified using the following specific primers: 50acgtctcgagcaaaggtgaggtgcagctggtggagtca30 (fw; in italics: XhoI restriction site) and 50 gacttccggagga gacggtgaccgt30 (rev; in italics: BspEI restriction site) for $\mathrm{VH}$; 50 ttgtgtgcactctgatattgtgatgtcccagt30 (fw; in italics: ApaLI restriction site) and 50ttgtactagtgctgcctttcagctccagcttggt3 (rev; in italics: SpeI restriction site) for VL. The VH and VL fragments were then cloned into the vector PUT-epsilon SIP225 to obtain both the scFv and the small immunoprotein (SIP) format of the C6 mAb.25,29 Mouse uteroglobin (UG) cDNA was provided by GenScript Corporation (Piscataway, NJ). For the generation of the cDNA encoding for C6-UG, we amplified the UG cDNA preceded by a sequence encoding for a 15 amino acid-linker30 by PCR. The resulting amplification product was digested using BspEI and EcoRI and inserted in the pcDNA3.1 vector (Invitrogen, Carlsbad, CA) downstream the C6 scFv. All PCR reactions were performed with high-fidelity Pwo DNA Polymerase (Roche Diagnostics, Basel, Switzerland) 
according to the manufacturer's instructions. All restriction enzymes were from Roche Diagnostics. All the PCR products and digested cDNA fragments were purified with the High Pure PCR Purification Kit (Roche Diagnostics). The digested vectors were purified using the Qiaquick Gel Extraction Kit (Qiagen). The cDNA construct was used to transform DH5a competent bacteria cells, and selected clones were screened by PCR. The plasmid DNA was purified from positive clones using the Pure- Link HiPure Plasmid Filter Maxiprep kit (Invitrogen), and the DNA sequence was confirmed by sequencing the DNA on both strands. The purified construct was used to transfect CHO cells (ATCC) using Lipofectamine 2000 CD Reagent (Invitrogen) according to the manufacture's instructions. Transfectomas were grown in RPMI 1640 (Euroclone, Pavia, Italy) supplemented with 10\% FCS (Biochrom AG, Berlin, Germany) and $4 \mathrm{mM}$ L-glutamine (Invitrogen), and selected using $500 \mathrm{lg} / \mathrm{ml}$ of Geneticin (G418, Calbiochem, San Diego, CA). The supernatants of the G418 resistant clones were screened for the production of the fusion proteins by ELISA using the recombinant fragment 7.EDB.8.926 as antigen (for C6-UG). A rabbit polyclonal anti-mouse UG antibody, produced in our laboratories, was used as secondary antibody, and a peroxidase-conjugated anti-rabbit polyclonal IgG (Pierce, Rockford, IL) as tertiary antibody. The C6-UG fusion protein was immunopurified from the conditioned medium of the cells on 7.EDB.8.9 conjugated to $\mathrm{CNBr}$-activated Sepharose 4B and analyzed in native conditions by fast protein liquid chromatography on a Superdex200 column and by SDS-PAGE under reducing and nonreducing conditions.

\section{Radioiodination and biodistribution experiments using the fusion protein C6-uteroglobin}

C6-UG was radioiodinated as previously described25 with iodine 125 using the Iodogen method (Pierce). After labeling, the immunoreactivity of the fusion protein was more than $90 \% \mathrm{Nu} / \mathrm{Nu}$ nude mice (Charles River, Italy) with subcutaneously implanted SKMEL28 human melanoma were injected intravenously with about $5 \lg (4 \mathrm{lCi} ; 0.148 \mathrm{MBq})$ of protein in $100 \mathrm{ll}$ saline solution. Three animals were used for each time point. Mice were sacrificed at 4, 24, 48 and $96 \mathrm{hr}$ after injection. The organs including tumor were weighed and the radioactivity was counted in a gamma counter. Targeting results are expressed as a percent of the injected dose per gram of tissue (\%ID/g). Housing, treatment and sacrifice of animals followed national legislative provisions (Italian law no. 116 of 27 January, 1992).

Results Generation and characterization of the mAb C6 specific for a FN epitope within the type III repeat 8, which is cryptic when the EDB is deleted and unmasked when the EDB is inserted 
Mice were immunized using the recombinant FN fragment composed of the type III repeats 7.EDB.8.9 (Figs. 1a and 1b). After fusion of the immunized animals' splenocytes with SP2/0 myeloma cells, the resulting clones were tested by ELISA on plasma FN and FN from the spent medium of WI38VA fibroblasts that contains high amounts of B-FN. The clones, positive with FN from transformed cells and negative with plasma FN, were further tested using plasma FN, WI38VA FN and different recombinant FN fragments (Fig. 1b) composed of various type III repeats: specifically, EDB.8; 7.EDB; 7; 8; 7.8.9; 7.EDB.8.9. None of the clones was positive with all EDB-containing fragments indicating that we did not obtain clones specific for EDB, this is not surprising because the EDB is highly conserved and is identical in human and mouse. Similarly, none of the clones reacted with the fragment 7.8.9 as expected, because the clones were selected on the basis of negative reaction with plasma FN. We obtained a group of clones that were positive with 7.EDB.8.9 and 7.EDB, but negative with all the other clones. Thus, the epitope recognized by these clones is very likely located on an epitope on the repeat 7 and cryptic when the EDB is omitted from FN molecules and, thus, similar to the already described mAb BC1.5,23 As a result, we focused on a 2nd group of clones reacting with the EDB.8, 7.EDB.8.9 and that were negative with all the other FN fragments, because this finding suggested the presence of a novel cryptic epitope on the type III repeat 8. Figure 1c shows the results obtained by Western blots performed using the Ig purified from the spent medium of one of these new clones, C6, with plasma FN, FN from WI38VA fibroblasts and different FN recombinant fragments. Figure 1c also shows a similar blot using the mAb BC1, specific for an epitope on the repeat 7 (see Fig. 1a). Western blot results demonstrated that the epitopes recognized by the mAbs BC1 and C6 are different and localized on repeats III7 and III8, respectively. In addition, C6, as well as BC1, reacts with B-FN, but not with plasma FN that does not contain EDB. Figure 1d shows an ELISA assay of different concentrations of purified C6 tested on different FN recombinant fragments. Purified C6 reacts only with the type III repeat 8 and with all the FN recombinant fragments containing both the repeat 8 and EDB. No reaction was observed with FN fragments in which the repeat III8 was not included. These results confirmed the conclusion that the epitope recognized by the mAb C6 is localized within the type III repeat 8, and that the presence of the EDB in the FN molecule unmasks it. The new mAb C6 was demonstrated to be an IgG1, and BIAcore experiments demonstrated a dissociation constant of 10 $\mathrm{nM}$ using the FN recombinant fragment 7.EDB.8.9 as antigen (data not shown).

\section{Immunohistochemical studies}

Using the mAb C6, we carried out immunohistochemical studies on cryostat sections of specimens from normal adult human tis- sues (breast, heart, oesophagus, muscle, thymus, spleen, thyroid, 
nerve, brain, testis, liver, parotid and lymph node), from human cancer (mesothelioma, melanoma, lung adenocarcinoma and glioblastoma) and from murine experimental tumors. We found that, identically to the results obtained with the mAbs BC1 and CGS1 (a human recombinant antibody that reacts directly with the EDB),26 all the normal human tissues tested were negative, whereas the human neoplastic tissues were strongly positive (Fig. 2). These 3 antibodies reacted with identical structures in neoplastic tissues, with the exception of the F9 murine teratocarcinoma, in which CGS1 was the only antibody to react; the other 2 mAbs, BC1 and C6, were negative (Fig. 3). This occurs because CGS1 directly recognizes the EDB, which is identical in human and mouse, thus ensuring its reaction equally well with human and mouse B-FN. In contrast, C6 and BC1 react with human specific epitopes on repeats III8 and III7, respectively, and consequently do not recognize murine B-FN.

\section{Generation of the $\mathrm{C} 6$ mini-antibody}

IgGs are large molecules and their penetration in tissues is poor. We therefore generated a C6 miniantibody to evaluate tumor targeting in tumor-bearing mice. The cDNA variable regions $\mathrm{VH}$ and VL of the mAb C6 were cloned as reported in Material and methods and sequenced on both strands. Using the 2 variable regions, we generated a scFv and attempted to construct a SIP25 by ligating the scFv to the CH4 of the secretory isoform S2 of human IgE. Because of the very low solubility of the C6 SIP format, we generated a novel fusion protein with murine UG, a small and extremely soluble homodimeric protein.31,32 As described in the Material and methods section, we prepared the cDNA construct of C6-UG, depicted in Figure 4b, and transfected CHO cells. Figure 4a depicts the C6-UG molecule. This fusion protein, expressed in cultured CHO cells at about $4 \mathrm{mg} / \mathrm{l}$, presented a very good solubility, stability and absence of aggregate formation at concentrations higher than $2 \mathrm{mg} / \mathrm{ml}$. In addition, it was possible to lyophilize and reconstitute this protein without any loss of protein or immunoreactivity (data not shown). Figure 4c shows an SDS-PAGE of the purified C6-UG fusion protein. In SDS-PAGE, the protein migrates as a homodimer, in nonreducing conditions and as a monomer, in reducing conditions, with the expected sizes of about 75 and $38 \mathrm{kDa}$, respectively. The results demonstrated that in nonreducing conditions the protein is a $100 \%$ covalently linked homodimer, and the size exclusion chromatography profiles (Fig. 4d) showed a single peak with a retention volume corresponding to the molecular mass of the homodimer. Tumor targeting experiments were carried out in tumor-bearing mice using radioiodinated C6-UG and the human melanoma SKMEL28. Figure 4e shows the percentage of the injected dose per gram of tissue (\%ID/g) at different times after injection of the radioiodinated protein in the tumor and in blood. The results indicate a very fast clearance of C6-UG from blood. 
Figure $4 \mathrm{f}$ shows the ratios of the \%ID/g of tumor and of blood. The ratio of the \%ID/g in the tumor versus other organs was higher than 10 in all cases (data not shown).

\section{Discussion}

Expression of the EDB of FN is regulated by alternative splicing, a process that in some ECM proteins is modulated by cytokines and extracellular/intracellular pH.34-36 We originally discovered the EDB through amino acid sequence analysis of proteolytic fragments of FN from normal and transformed human cells, detecting an extra sequence preferentially included in FN from cultured transformed cells.16 Independently and almost simultaneously, the EDB was demonstrated by ribonuclease protection experiments on mRNA in rat and confirmed in human and was called EIIIB and EDII, respectively.37,38 Subsequently, we generated a mAb specific for BFN, BC1,5 and demonstrated by immunohistochemistry that, although FN containing the EDB is undetectable in the tissues of healthy adults (with very rare exceptions, such as the recurrent physiological processes of tissue remodeling and angiogenesis occurring in the female reproductive system), it is, in contrast, abundant in fetal and neoplastic tissues. This antibody was widely used thereafter by different groups, which in numerous studies confirmed that B-FN was a pantumoral marker.18 By means of BC1, we also demonstrated that B-FN is an excellent marker of angiogenesis21,22 and that the mAb could be used to selectively target, in vivo, experimental tumors.39 All of these results prompted the generation of human recombinant antibodies specific for the EDB for diagnostic and therapeutic purposes.26,40 One of these, L19, showed a high affinity for the EDB and performed very well in tumor targeting experiments.40 Such promising findings underpinned the subsequent generation of a number of fusion proteins and conjugates for selective delivery of drugs on tumors.41,42 After successful preclinical investigations, 3 of these fusion proteins25,30,43 were produced by the Italian biotech firm Philogen SPA under GMP conditions and used in various phase I/II clinical trials for cancer therapy.44-49 It has been previously reported that the insertion of the EDB between the type III repeats 7 and 8 induces a conformational modification that unmasks a cryptic sequence and hinders others.23 In fact, the BFN-specific mAb BC1 reacts with an epitope localized on the repeat III7 that is accessible only when the EDB is included in the FN molecule; on the contrary, the mAb IST6 reacts only with EDB-free FN, indicating that the insertion of the extra domain either destroys or hinders sequences that may have a biological function. We now describe a new epitope localized on the repeat III8 that is hindered when the EDB is omitted but unmasked when the EDB is inserted within the FN molecule. We generated a high-affinity mAb for this epitope, C6, that specifically recognizes B-FN by means of ELISA, immunohistochemistry or Western blot. These data are in line with a recent 
report50 that describes the crystal structure of the interface between the EDB and its adjacent domain III8. The same work reported, together with other modifications, that the insertion of the EDB between repeats III7 and III8 unmasks the FG loop of repeat III8, which is hindered by the CC' loops of repeat III7 when the EDB is omitted. We also evaluated the tumor targeting performance of C6. Because IgG is such a large molecule, a factor that limits its penetration in tissues, we previously demonstrated that divalent, covalently linked homodimers penetrate better in tissues and have a faster clearance. In the case of the scFv L19 specific for the EDB,40 to achieve an efficient tumor targeting, we therefore adopted the SIP25 format. The SIP, first reported by Li et al.,29 is constituted by the fusion of a scFv to the $\mathrm{CH} 4$ domain of the secretory isoform S2 of human IgE. This domain contains a cysteine at the $\mathrm{COOH}$ termini that covalently stabilizes the dimer through an interchain disulfide bond. The oxidized form of the SIP has a molecular size of about $80 \mathrm{kDa}$, thereby guaranteeing faster blood clearance and better penetration into neoplastic tissues compared to IgG. The SIP format of L19 has been used in radioimmunotherapy clinical trials on different kinds of cancers. We thus cloned the variable regions of C6 and prepared a scFv to generate a C6 in the SIP format. However, we found that the C6-SIP format was very poorly soluble and that it aggregated easily. We therefore decided to use a different approach, and instead of the CH4 domain of IgE, we used UG, a small, extremely soluble and stable homodimer. UG is a small, globular, nonglycosylated, homodimeric secreted protein, which was discovered independently by 2 groups in the 1960s in rabbit uterus.51,52 It is the 1st member of a new superfamily of proteins, the so-called secretoglobins (Scgb).53 UG is present in the blood at a concentration of about $15 \mathrm{lg} / \mathrm{ml}$ and is found in urine and in other body fluids. The UG monomer is composed of about 70 amino acids, depending on the species; the 2 subunits are joined in an antiparallel fashion by disulfide bridges established between 2 highly conserved cysteine residues in amino- and carboxy-terminal positions. The exact functions of UG are not yet clear, but the protein has been reported to have anti-inflammatory properties because of its ability to inhibit the soluble phospholipase A2 (for exhaustive reviews on UG see refs. 31, 32). Using this approach, we were able to generate a very stable and very soluble covalently bound divalent C6. On the basis of this experience, we prepared other scFv fusion proteins using UG as a central skeleton, and we were able to prepare bivalent, tetravalent and dual-specific tetravalent molecules all with good solubility and stability (Sassi et al., manuscript in preparation). Tumor targeting was investigated through biodistribution studies by injecting radioiodinated C6-UG in tumor-bearing mice. The \%ID/g of the tumor was lower compared to the ratio produced by the SIP format of L19 in the same tumor, but the residence time of radiolabeled C6-UG was longer: in fact, 4 days after injection, the amount of the radiolabeled protein in the tumor was only about 20\% lower than it was 4 hr after injection, 
whereas the amount of the L19-SIP 4 days after injection was nearly 4 times lower compared to the \%ID/g at $4 \mathrm{hr}$. At present, we cannot explain such a long and stable residence time, but it was reported that the EDB, with which L19 reacts, is very sensitive to various proteolytic enzymes, whereas the repeat III8 is much more stable.16 Therefore, the higher residence time in the tumor of C6 compared to L19 could be due to the differing resistance of the 2 epitopes, or of the flanking sequences, to proteolytic enzymes. The lower amount of C6 accumulating in the tumor with respect to L19-SIP could be explained by the fact that the B-FN in the experimental tumor model used human melanoma SKMEL28, originated in a small percentage from human tumor cells but the majority from the murine cells of the host such as fibroblasts, endothelial cells and other stroma cells. Because L19 is able to bind both human and mouse B-FN, whereas C6 can bind only the human B-FN present in the tumor, this could explain the lower C6-UG accumulation in the tumor with respect to L19-SIP. In conclusion, the mAb C6 represents a new tool for the study of the potential biological functions of hindered sequences that the inclusion of the EDB makes accessible. Its epitope, moreover, provides an additional and stable angiogenesis target.

\section{Acknowledgements}

The authors thank Mrs. Sibel S€umer for her editorial assistance in the preparation of the manuscript and Mr. Thomas Wiley for manuscript revision. They are indebted with Dr. Marco Bestagno for his suggestions in the preparation of the primers for cloning the variable regions of C6 and with Dr. Alessandro Pini and Dr. Barbara Lelli for helping in BIAcore experiments.

\section{References}

1. Folkman J. Angiogenesis in cancer, vascular, rheumatoid and other disease. Nat Med 1995;1:27-31.

2. Risau W, Lemmon V. Changes in the vascular extracellular matrix during embryonic vasculogenesis and angiogenesis. Dev Biol 1988;125:441-50.

3. Yamada KM, Clark RAF. Provisional matrix. In: Clark RAF, ed. The molecular and cellular biology of wound repaired. New York: Plenum Press, 1996.51-93.

4. Castellani P, Siri A, Rosellini C, Infusini E, Borsi L, Zardi L. Transformed human cells release different fibronectin variants than do normal cells. J Cell Biol 1986;103:1671-7.

5. Carnemolla B, Balza E, Siri A, Zardi L, Nicotra MR, Bigotti A, Natali 
PG. A tumor-associated fibronectin isoform generated by alternative splicing of messenger RNA precursors. J Cell Biol 1989;108:

1139-48.

6. Nicolo G, Salvi S, Oliveri G, Borsi L, Castellani P, Zardi L. Expression of tenascin and of the ED-B containing oncofetal fibronectin isoform in human cancer. Cell Differ Dev 1990;32:401-8. 7. Borsi L, Carnemolla B, Nicolo G, Spina B, Tanara G, Zardi L. Expression of different tenascin isoforms in normal, hyperplastic and neoplastic human breast tissues. Int J Cancer 1992;52:688-92.

8. Leprini A, Querze G, Zardi L. Tenascin isoforms: possible targets for diagnosis and therapy of cancer and mechanisms regulating their expression. Perspect Dev Neurobiol 1994;2:117-23.

9. Oyama F, Hirohashi S, Shimosato Y, Titani K, Sekiguchi K. Deregulation of alternative splicing of fibronectin pre-mRNA in malignant human liver tumors. J Biol Chem 1989;264:10331-4.

10. Oyama F, Hirohashi S, Shimosato Y, Titani K, Sekiguchi K. Qualitative and quantitative changes of human tenascin expression in transformed lung fibroblast and lung tumor tissues: comparison with fibronectin. Cancer Res 1991;51:4876-81.

11. Pankov R, Yamada KM. Fibronectin at a glance. J Cell Sci 2002;115:3861-3.

12. Hynes RO. Fibronectins. New York: Springer-Verlag, 1990.

13. Ruoslahti E. The RGD story: a personal account. Matrix Biol 2003;22:459-65.

14. Zardi L, Cianfriglia M, Balza E, Carnemolla B, Siri A, Croce CM. Species-specific monoclonal antibodies in the assignment of the gene for human fibronectin to chromosome 2. EMBO J 1982;1:929-33. 15. Borsi L, Carnemolla B, Castellani P, Rosellini C, Vecchio D, Allemanni G, Chang SE, Taylor-Papadimitriou J, Pande H, Zardi L. Monoclonal antibodies in the analysis of fibronectin isoforms generated by alternative splicing of mRNA precursors in normal and transformed human cells. J Cell Biol 1987;104:595-600.

16. Zardi L, Carnemolla B, Siri A, Petersen TE, Paolella G, Sebastio G, Baralle FE. Transformed human cells produce a new fibronectin isoform 
by preferential alternative splicing of a previously unobserved exon. EMBO J 1987;6:2337-42.

17. Kaczmarek J, Castellani P, Nicolo G, Spina B, Allemanni G, Zardi

L. Distribution of oncofetal fibronectin isoforms in normal, hyperplastic and neoplastic human breast tissues. Int J Cancer 1994;59:

$11-16$.

18. Kosmehl H, Berndt A, Katenkamp D. Molecular variants of fibronectin and laminin: structure, physiological occurrence and histopathological aspects. Virchows Arch 1996;429:311-22.

19. Norton PA, Hynes RO. Alternative splicing of chicken fibronectin in embryos and in normal and transformed cells. Mol Cell Biol 1987;7:4297-307.

20. Ffrench-Constant C, Van de Water L, Dvorak HF, Hynes RO. Reappearance of an embryonic pattern of fibronectin splicing during wound healing in the adult rat. J Cell Biol 1989;109:903-14.

21. Castellani P, Viale G, Dorcaratto A, Nicolo G, Kaczmarek J, Querze G, Zardi L. The fibronectin isoform containing the ED-B oncofetal domain: a marker of angiogenesis. Int J Cancer 1994;59:612-18.

22. Castellani P, Borsi L, Carnemolla B, Biro A, Dorcaratto A, Viale GL, Neri D, Zardi L. Differentiation between high and low-grade astrocytoma using a human recombinant antibody to the extra domain-B of fibronectin. Am J Pathol 2002;161:1695-700.

23. Carnemolla B, Leprini A, Allemanni G, Saginati M, Zardi L. The inclusion of the type III repeat ED-B in the fibronectin molecule generates conformational modifications that unmask a cryptic sequence. J Biol Chem 1992;267:24689-92.

24. Zardi L, Carnemolla B, Siri A, Santi L, Accolla RS. Somatic cell hybrids producing antibodies specific to human fibronectin. Int J Cancer 1980;25:325-9.

25. Borsi L, Balza E, Bestagno M, Castellani P, Carnemolla B, Biro A, Leprini A, Sepulveda J, Burrone O, Neri D, Zardi L. Selective targeting of tumoral vasculature: comparison of different formats of an antibody (L19) to the ED-B domain of fibronectin. Int J Cancer 2002;102:75-85. 
26. Carnemolla B, Neri D, Castellani P, Leprini A, Neri G, Pini A, Winter G, Zardi L. Phage antibodies with pan-species recognition of the oncofoetal angiogenesis marker fibronectin ED-B domain. Int J Cancer 1996;68:397-405.

27. Tarli L, Balza E, Viti F, Borsi L, Castellani P, Berndorff D, Dinkelborg L, Neri D, Zardi L. A high-affinity human antibody that targets tumoral blood vessels. Blood 1999;94:192-8.

28. Chomczynski P, Sacchi N. Single-step method of RNA isolation by acid guanidinium thiocyanate-phenol-chloroform extraction. Anal Biochem 1987;162:156-9.

29. Li E, Pedraza A, Bestagno M, Mancardi S, Sanchez R, Burrone O. Mammalian cell expression of dimeric small immune proteins (SIP). Protein Eng 1997;10:731-6.

30. Borsi L, Balza E, Carnemolla B, Sassi F, Castellani P, Berndt A, Kosmehl H, Biro A, Siri A, Orecchia P, Grassi J, Neri D, et al. Selective targeted delivery of TNFa to tumor blood vessels. Blood 2003;102:4384-92.

31. Mukherjee AB, Zhang Z, Chilton BS. Uteroglobin: a steroid-inducible immunomodulatory protein that founded the secretoglobin superfamily. Endocr Rev 2007;28:707-25.

32. Zhang Z, Kundu GC, Zheng F, Yuan CJ, Lee E, Westphal H, Ward J, DeMayo F, Mukherjee AB. Insight into the physiological function(s) of uteroglobin by gene-knockout and antisense-transgenic approaches. Ann N Y Acad Sci 2000;923:210-33.

33. Morize I, Surcouf E, Vaney MC, Epelboin Y, Buehner M, Fridlansky F, Milgrom E, Mornon JP. Refinement of the C222(1) crystal form of oxidized uteroglobin at 1.34 A resolution. J Mol Biol 1987;194: 725-39.

34. Borsi L, Balza E, Gaggero B, Allemanni G, Zardi L. The alternative splicing pattern of the tenascin-C pre-mRNA is controlled by the extracellular pH. J Biol Chem 1995;270:6243-5.

35. Borsi L, Castellani P, Risso AM, Leprini A, Zardi L. Transforming growth factor-b regulates the splicing pattern of fibronectin messenger RNA precursor. FEBS Lett 1990;261:175-8. 
36. Balza E, Borsi L, Allemanni G, Zardi L. Transforming growth factor b regulates the levels of different fibronectin isoforms in normal human cultured fibroblasts. FEBS Lett 1988;228:42-4.

37. Schwarzbauer JE, Patel RS, Fonda D, Hynes RO. Multiple sites of alternative splicing of the rat fibronectin gene transcript. EMBO J 1987;6:2573-80.

38. Gutman A, Kornblihtt AR. Identification of a third region of cell-specific alternative splicing in human fibronectin mRNA. Proc Natl Acad Sci USA 1987;84:7179-82.

39. Mariani G, Lasku A, Balza E, Gaggero B, Motta C, Di Luca L, Dorcaratto A, Viale GA, Neri D, Zardi L. Tumor targeting potential of the monoclonal antibody BC-1 against oncofetal fibronectin in nude mice bearing human tumor implants. Cancer 1997;80:

2378-84.

40. Pini A, Viti F, Santucci A, Carnemolla B, Zardi L, Neri P, Neri D. Design and use of a phage display library. Human antibodies with subnanomolar affinity against a marker of angiogenesis eluted from a two-dimensional gel. J Biol Chem 1998;273:21769-76.

\section{HUMAN FIBRONECTIN CRYPTIC SEQUENCE 757}

41. Neri D, Bicknell R. Tumour vascular targeting. Nat Rev Cancer 2005;5:436-46.

42. Kaspar M, Zardi L, Neri D. Fibronectin as target for tumor therapy. Int J Cancer 2006;118:1331-9.

43. Carnemolla B, Borsi L, Balza E, Castellani P, Meazza R, Berndt A, Ferrini S, Kosmehl H, Neri D, Zardi L. Enhancement of the antitumor properties of interleukin-2 by its targeted delivery to the tumor blood vessel extracellular matrix. Blood 2002;99:1659-65.

44. Menrad A, Menssen HD. ED-B fibronectin as a target for antibodybased cancer treatments. Expert Opin Ther Targets 2005;9:491-500.

45. Santimaria M, Moscatelli G, Viale GL, Giovannoni L, Neri G, Viti F, Leprini A, Borsi L, Castellani P, Zardi L, Neri D, Riva P. Immunoscintigraphic detection of the ED-B domain of fibronectin, a marker of angiogenesis, in patients with cancer. Clin Cancer Res 2003;9:571-9. 46. Sauer S, Erba PA, Petrini M, Menrad A, Giovannoni L, Grana C, 
Hirsch B, Zardi L, Paganelli G, Mariani G, Neri D, Durkop H, Menssen HD. Expression of the oncofetal EDB containing fibronectin in hematologic tumors enables EDB targeted 131 I-L19SIP radioimmunotherapy in Hodgkin lymphoma patients. Blood 2009;113:2121-2.

47. Del Conte G, Tosi D, Fasolo A, Chiesa C, Erba PA, Grana CM, Menssen HD, Mariani G, Bombardieri E, Gianni L. A phase I trial of antifibronectin 131I-L19-small immunoprotein (L19-SIP) in solid tumors and lymphoproliferative disease. J Clin Oncol (ASCO Annual Meetings Proceedings) 2008;26:2575.

48. Curigliano G, Spitalieri G, De Pas T, Noberasco C, Giovannoni L, Menssen HD, Zardi L, Milani A, Neri D, de Braud F. A dose finding pharmacokinetic study of the tumor-targeting human L19-IL2 monoclonal antibody-cytokine fusion protein in patients with advanced solid tumors. J Clin Oncol (ASCO Annual Meeting Proceedings) 2007;25:3057.

49. Johannsen M, Roemer A, Spitaleri G, Curigliano G, Giovannoni L, Menssen HD, Zardi L, Neri D, Miller K, de Braud FG. Phase I/II study of the tumor-targeting human L19-IL2 monoclonal antibody-cytokine fusion protein in patients with advanced renal cell carcinoma. J Clin Oncol (ASCO Annual Meeting Proceedings) 2008;26:16032. 50. Bencharit S, Cui CB, Siddiqui A, Howard-Williams EL, Sondek J, Zuobi-Hasona K, Aukhil I. Structural insights into fibronectin type III domain-mediated signaling. J Mol Biol 2007;367:303-9.

51. Krishnan RS, Daniel JC, Jr. "Blastokinin": inducer and regulator of blastocyst development in the rabbit uterus. Science 1967;158: $490-2$.

52. Beier HM. Uteroglobin: a hormone-sensitive endometrial protein involved in blastocyst development. Biochim Biophys Acta 1968; 160:289-91.

53. Klug J, Beier HM, Bernard A, Chilton BS, Fleming TP, Lehrer RI, Miele L, Pattabiraman N, Singh G. Uteroglobin/Clara cell 10-kDa family of proteins: nomenclature committee report. Ann N Y Acad Sci 2000;923:348-54. 